\title{
The Correlation between EFL PBT (Paper based TOEFL) Prediction and Verbal Assessment Test Scores of Engineering Students
}

\author{
Luh Mas Ariyati \\ Universitas Negeri Surabaya \\ luhmas bahasa@,its.ac.id
}

\author{
Lies Amin Lestari \\ Universitas Negeri Surabaya \\ lieslestari@unesa.ac.id
}

\begin{abstract}
An EFL Test, a English assessment-PBT prediction is developed by ITS (Sepuluh Nopember Institute of Technology Surabaya) Centre for Languages and Cultures to measure the students' English proficiency as a part of their graduation requirements. The test has caused the majority of students postpone their graduation. Many efforts have been carried out to improve the students' score, but the results is not fully satisfying. To seek better ways to increase the students' English competence in the future, a study on the correlation between Verbal Assessment Test (VAT) as indicator of intelligence and the increase of students' EFL score test was carried out. The well-known SILL questionairre developed by Oxford (1990) was employed to find the such correlation. The subjects of the study was students of 2012 batch from 5 different faculties in ITS. The analysis was conducted using structural equation modelling (SEM) statistcial method and combined with personal interview with $10 \%$ of the students representing the high, average, and low achievers. Result shows that the high achievers possess higher VAT scores than those of the average and low ones. Moreover, the high achievers answer the questionnaire better and with very little mistakes than the others.
\end{abstract}

Keywords-EFL Score, PBT, VAT, SEM, interview

\section{INTRODUCTION}

English has been well-known as the most used international language in the world as indicated by McKay [1]. It is further understood that English is not only used by people in inner circle English countries such as the United Kingdom, Australia, and USA but also used by people in the outer and expanding circles including Indonesia [2][3]. Moreover, English is at present found to be very important in academic [4].

In order to satisfy the English criteria for academic purposes, several international standardized tests are available including TOEFL and IELTS [5]. TOEFL (Test of English as a Foreign Language) is a standardized test to measure the English language ability of non-native speakers wishing to enrol in English-speaking universities such as to USA, whereas IELTS (the International English Language Testing System) is known as an international standardized test of English language proficiency for non-native English language speakers wishing to register to universities such as in the UK and Australia. The format of paper-based TOEFL test is modified by ITS in such a way hence can be administered to wider mass of students in sequential time and it is termed as EFL test.

Never-ending observations have been carried out by language teachers and researchers on some learners who acquire English as a second or foreign language more quickly and effectively than that of others [6][7][8]. Findings showed that more proficient students acquire their English skill because they apply certain strategies. The present study was intended to identify the correlation between EFL test score and Verbal Assessment Test (VAT) and assisted by the use of SILL.

VAT is known as the ability to comprehend and reason language concepts expressed through words [9]. A VAT is a form of aptitude test used by interviewers to find out how well a candidate can assess verbal logic, and how successfully they can extract meaning from complex written information.

The result of a strategy inventory for language learning (SILL) introduced by Oxford [10] consisting of six strategies: metacognitive, cognitive, memory, compensation, affective, and social strategies, was used and the analysis was carried out using this popular method.

\section{METHODS}

\section{A. Subject of the study}

The subjects of the study were engineering students from 5 Faculties at ITS who have EFL test scores between 460 and 600 based on their final or latest tests. They were undergraduate students from batch 2012 and studying at the Faculty of Mathematics and Sciences (FMIPA), Faculty of Industrial Technology, Faculty of Civil Engineering and Planning (FTSP), Faculty of Marine Technology (FTK), and Faculty of Information Technology (FTIf). Four hundred out of 4,000 students (or $10 \%$ of the population) took part in the research. Furthermore, 40 students (or $10 \%$ out of 400 ones) 
are interviewed in order to map their English ability. Finally, 6 students were selected for the current study, based on their final EFL test score, in order to describe the correlation between EFL test score and VAT.

\section{B. Research instrument}

To solve the learners' problem, the focus of the study was to find out the correlation between the achieved EFL test scores and VAT and their association to SILL.

\section{TOEFL PBT or EFL Test}

The TOEFL paper-based test (PBT) is a three-section assessment that is offered in places where the TOEFL internetbased test (iBT) is not available. The PBT evaluates listening, structure and written expression as well as reading skills representing the knowledge of English conventions through four skills such as listening comprehension, speaking, reading, and writing English. Total timing for the PBT is 110-120 minutes, which includes 140 questions.

The PBT's listening comprehension section is intended to "measure the ability to understand spoken English." Testtakers are given 30-40 minutes to answer 50 questions. The questions in this section are all multiple choice, and they are based on audio recordings of conversations and lectures. Correct answers are converted to a scaled listening comprehension section score of 31 to 68 .

The structure and written expression section of the PBT "measures the ability to recognize language appropriate for standard written English," and it covers 40 questions in 25 minutes. Structure and written expression questions are also multiple choice. Two types of exercises are included: 15 questions in which test-takers must complete sentences with the best word choice, and 25 questions that require test-takers to choose which underlined word or phrase must be changed in order to correct the given sentence. Scaled structure and written expression scores are reported from 31 to 68 .

The reading comprehension is designed to measure "the ability to understand non-technical reading material." Students are allowed 55 minutes to answer 50 multiple-choice questions on reading passages intended for non-specialists. Questions ask about information stated or implied in reading passages and the meaning of specific words or phrases. The scoring scale for PBT reading comprehension ranges from 31 to 67 .

In addition to the scaled sectional scores noted above, students receive a total score for the PBT on a scale of 310 to 677 . This total score is built from the listening comprehension, structure and written expression, and reading comprehension sections.

\section{Verbal Assessment Test}

Verbal assessment/reasoning test (VAT) measures understanding and reasoning using concepts framed in words [11]. It aims at evaluating ability to think constructively, rather than at simple fluency or vocabulary recognition. VAT are often used as entrance examinations by schools, colleges and universities to select the most able applicants. They are also used by a growing number of employers as part of the selection or recruitment process. Large graduate training schemes are increasingly using VAT to distinguish among applicants. The types of VAT candidates face in these assessments are typically looking to assess understanding and comprehension skills. Furthermore, in Indonesia VAT score is taken from academic potency tests (TPA) with minimum score of 200 and maximum score of 800 .

\section{Strategy Inventory for Language Learning (SILL)}

The strategy inventory for language learning (SILL) consists of 6 strategies, namely metacognitive, cognitive, memory compensation, affective and social strategies. In SILL, the preferred strategies used by learners are examined through the questionnaires. It uses a 5 Likert-scale for which the learners are asked to indicate their response $(1,2,3,4$, and 5) to a strategy description such as "I try to talk like native speakers." The question must be answered by choosing the true statement describing the language learning strategies used by the subject. It is believed that summative rating scales are among the most efficient and comprehensive ways to assess frequency of language learning strategy use [10]. Reliability of the SILL is high across many cultural groups. Validity of the SILL remains on its predictive and correlative link with language performance (course grades, standardized test score, ratings of proficiency), as well as its confirmed relationship to students' preferences [12].

The way the SILL result is calculated and evaluated. Furthermore, Oxford [10] classifies the range of score obtained from the questionnaire into 3 categories: (a) 1.2 to 2.4 as low, (b) 2.4 to 3.4 as medium, and (c) 3.5 to 5.0 as high.

\section{FINDINGS}

The results of EFL test, VR test, and SILL score are given in Table 1. The minimum EFL score is 467 and the maximum one is 600 . The minimum VR score is 452 and the maximum one is 620 . The minimum SILL score is 2.4 and the maximum one is 3.4. Such correlation is further shown in table 1 and Figures 1.

Table 1: Correlation between EFL score and VR test

\begin{tabular}{|c|c|c|c|c|}
\hline No & $\begin{array}{c}\text { Name of Student } \\
\text { (Status) }\end{array}$ & EFL Score & VR Test & SILL score \\
\hline 1 & Student A (Low) & 467 & 452 & 2.4 \\
\hline 2 & Student B (Low) & 477 & 512 & 3.4 \\
\hline 3 & Student C (Medium) & 513 & 476 & 3.4 \\
\hline 4 & Student D (Medium) & 530 & 560 & 3.2 \\
\hline 5 & Student E (High) & 563 & 584 & 3.4 \\
\hline 6 & Student F (High) & 600 & 620 & 3.2 \\
\hline
\end{tabular}




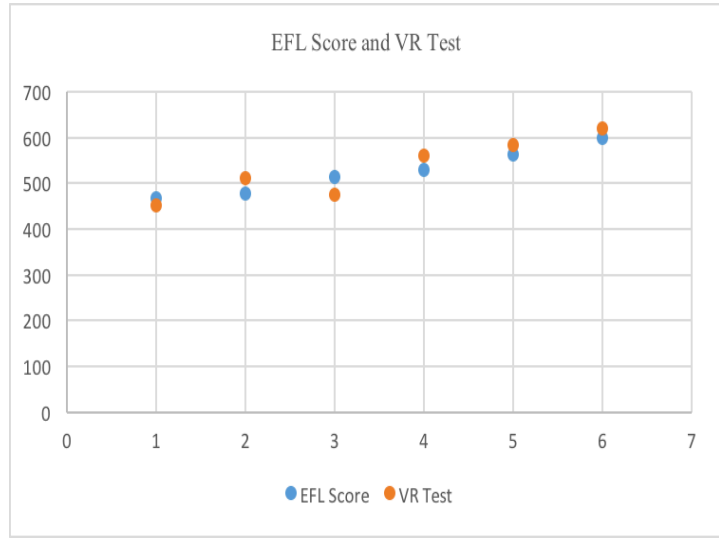

Figure 1: Correlation between EFL Score and VR Test

\section{DISCUSSION}

Six students were investigated based on their EFL score and VAT result. They are group into 3 categories, namely low skill (EFL score less than 500), medium skill (EFL score higher than 500 but lower than 550), and high skill (EFL score above 550). The results were tabulated in Table 1 and plotted in Figures 1.

Based on the results shown in Table 1, it is apparent that there is correlation between EFL score, VAT score and SILL result. The higher the VAT and SILL result, the better the EFL score of the students. This is an indication of correlation between language aptitude (represented by VAT score) and learning strategy (represented by SILL result) with English skill (represented by EFL Score).

Furthermore, it can be seen from Table 1 that there is a linear correlation between EFL score and result. The higher the VAT, the better the EFL score. However, there is a peculiar result shown by student no 3 in which lower VAT resulted in higher EFL score. The reason for this is due to lack of data within the present analysis, hence more data should be used in order to obtain more correct correlation. The most recommended statistical analysis, such as SEM (structural equation modelling) may be used to solve the more complex problem.

In term of the correlation between EFL score and SILL score, there is a good agreement between the two and indicated that the better the SILL score, the higher the EFL score. It is thus said that there is a good agreement between high VAT and SILL result against EFL score (see Figures 1 and 2), although more data is needed in order to obtain more concise conclusion.

Moreover, it can be said from interview activity that the higher achiever EFL score can speak English better than the lower achieve one. Example of answer of listening part given by respondents can be found in Table 2:
Table 2: Answers of student from interview activity

\begin{tabular}{|c|c|c|c|c|}
\hline No & Students & Low & Medium & High \\
\hline 1 & $\mathrm{~A}$ & $\begin{array}{c}\text { "Um I, I didn't } \\
\text { prepare } \\
\text { anything, um I } \\
\text { didn't take it } \\
\text { too serious ....." }\end{array}$ & & \\
\hline 2 & B & $\begin{array}{l}\text { "My prepare is } \\
\text { too um about } \\
\text { listening, } \\
\text { reading, ..." }\end{array}$ & & \\
\hline 3 & $\mathrm{C}$ & & $\begin{array}{l}\text { "Um well I } \\
\text { didn't prepare } \\
\text { that much, I just } \\
\text { um prepare by } \\
\text { watching film } \\
\text { or listening ...." }\end{array}$ & \\
\hline 4 & $\mathrm{D}$ & & $\begin{array}{c}\text { "I basically } \\
\text { study from a } \\
\text { book, um a } \\
\text { book that have } \\
\text { been sold ,.," }\end{array}$ & \\
\hline 5 & $\mathrm{E}$ & & & $\begin{array}{c}\text { "Well actually } \\
\text { for the listening } \\
\text { part, I always } \\
\text { watch movies } \\
\text { without the } \\
\text { subtitle ....." }\end{array}$ \\
\hline 6 & $\mathrm{~F}$ & & & $\begin{array}{c}\text { "My preparation } \\
\text { is nothing special } \\
\text { and I just read a } \\
\text { lot of English } \\
\text { literature ...." }\end{array}$ \\
\hline
\end{tabular}

It can be said from the above description that the higher the EFL score or the students, the better they master English together with wider vocabulary knowledge.

\section{CONCLUSION}

The research showed that there is good correlation between verbal assessment test (VAT) score and the achieved EFL score of engineering students at ITS. It is an indication that students with high VR has exposed him-/herself with English learning or skill properly. The findings are also supported by the SILL results which indicated that the higher VAT and EFL scores correlate well with the higher SILL score. As strong correlation was found out between the three instruments in this research, therefore it is suggested that similar research can be undertaken in different population with different period of time. It is proposed to confirm that the correlation applied in wider area consistently.

\section{REFERENCES}

[1] McKay, S L, Teaching English as an International Language: Rethinking Goals and Perspectives. Oxford University Press. New York, USA, 2002.

[2] Kachru, B B, Standards, Codification and Sociolinguistic Realism: the English Language in the Outer Circle. English in the World: Teaching and Learning the Language and Literatures. Ed. Randolph Quirk and Henry 
Widdowson. Cambridge University Press, pages 11-30, 1985.

[3] Graddol, D, English next. London, England: British Council.

Available

at http://www,britishcouncil.org/learning-research-englishnext.pdf, 2006.

[4] Conrad, S and Mauranen, A. The Corpus of English as Lingua Franca in Academic Settings. TESOL Quart., Vol 37, pp 513-527, 2003.

[5] Ariyati, L M and Lestari, L A, Language Learning Strategies Used by Engineering Students, TEFLIN Conference, Surabaya, Indonesia, 2015.

[6] Ariyati, L M and Lestari, L A, Multicultural Analysis on Test of English for International Communication (TOEIC) Preparation Textbooks Developed by Indonesian and Native Authors, TOEIC Conference, Surabaya, Indonesia, 2016.

[7] Dreyer, C., \& Oxford, R, Learning strategies and other predictors of ESL proficiency among Afrikaans speakers in South Africa. In R. L. Oxford (Ed.), in Language Learning Strategies andEnglish Proficiency of Chinese University Students -Regent University, 1996.
[8] Lightbown, P M and Spada, N, How Languages are Learned, Oxford University Press, Oxford, UK, 1999.

[9] Vance, S J, Language Learning Strategies: Is there a best way to teach them? (ERIC Document Reproduction Service No. ED438716), 1999.

[10] Oxford, R. L, Language learning strategies: What every teacher should know. New York: Newbury House Harper Collins, 1990.

[11] Aggarwal, R S, A Modern Approach to Verbal and NonVerbal Reasoning, S Chand and Company Ltd, New Delhi, India, 2007.

[12] Wenden, A, Learner Strategies in Language Learning, Englewood Cliff, Prentice Hall, New Jersey, 1987. 